\title{
The Role of Attention in Teacher Education: A Factor in the Quality of European Schooling
}

\begin{abstract}
The text is an article of reflection aiming to examine causes of disproportions between the amount of effort undertaken by leading international institutions in the field of education and the quality of European school systems measured by the attainment of curricular goals. As worrying trends have been observed mainly at the classroom level, psychological rather than organizational factors need to be examined. It is hypothesized that current didactic problems should be explained by attention rather than motivation deficits. The paper, therefore, analyzes various types and aspects of attention, tendencies to misdirect it as well as ways of building and maintaining attention in order to counteract distraction, boredom and overstimulation of both teachers and learners. Suggestions are also formulated for pre- and in-service teacher education programs which are postulated to give more emphasis to the role of attention as well as to provide a toolkit of verbal and non-verbal strategies which may help language teachers to elicit and sustain learners' attention without departing from the lesson scenario.
\end{abstract}

Keywords: quality, language learning, attention, distraction, coping strategies, teacher education

\section{Introduction}

For a long time the quality of education in Europe has been considered the responsibility of schools and teachers. Until the end of the 20th century governments took interest in education only in times of the implementation of major school reforms, while major international organizations such as the Council of Europe, the European Union, OECD and UNESCO focused on human rights, democratic citizenship, peaceful coexistence and intergovernmental 
collaboration, remaining firmly convinced that education lies beyond the scope of their interest. Yet, due to the growing awareness of its impact on economic growth, education kept slowly and systematically moving to become a sector of peripheral interest and then to take a prominent place on the European scene. For more than two decades now education in general and language education in particular, has been perceived as a sine qua non condition for successful economic development, thus becoming central to the concerns of all the international institutions. Yet, in spite of all the budgetary and organizational efforts quality of education remained unsatisfactory. Educational activity, therefore, turned first to promoting learner autonomy and then focused on motivation. The key, however, seems to lie in another factor, namely attention.

\section{Dissatisfaction with Education-In Search of Possible Causes}

The turn of the 20th and the 21st centuries marked a breakthrough for research conducted within the frames of the most important international institutions which turned to the analysis of school systems and their effectiveness. The Organization for Economic Co-operation and Development implemented two cyclic studies: PISA-Program for International Student Assessment (PISA) conducted every three years since 2000 and TALIS-Teaching and Learning International Survey conducted every five years since 2008, while the United Nations Educational, Scientific and Cultural Organization and its International Association for Evaluation of Educational Achievement developed PIRLSProgress in International Reading Literacy Study conducted every five years since 2001. The European Union completed an analysis of language education through SurveyLang-The First European Survey on Language Competences. Results, although optimistic for some countries, in most cases prove far from satisfactory (European Commission, 2012; OECD, 2018a; OECD, 2018b; Mullis et al., 2017).

At the same time all the organizations focused on designing strategies to support teaching and learning. The Council of Europe constructed and extended the Common Framework of Reference for Languages-teaching, learning and assessment (Council of Europe, 2001; Council of Europe, 2018). OECD initiated an overall diagnosis of education in member countries on the basis of which the concept of key qualifications was born. The study led to the selection of eight competencies adopted by the European Union and widely promoted via numerous EU activities and projects (European Commission, 2019). The European Union focused on the organization of language education which gained a high status as a result of the Lisbon 
Strategy with its "mother tongue plus 2 other languages" formula (European Commission, 2002; European Commission, 2005). The European Centre for Modern Languages in Graz launched projects aimed at raising the quality of language education and tackling issues caused by mobility and the resulting differences between learners' first languages and languages of schooling (www.ecml.at). In parallel all the governments of the EU member states have intensified efforts to provide proper infrastructure for schools and to control class sizes for language education offered therein (Baidak et al., 2017).

Despite the concerted international intellectual and financial investment, numerous problems remain unresolved, while educational systems meet with more and more criticism. Dissatisfaction has been voiced not only by researchers, but also by all the actors of the educational scene. Research launched by the OECD in 2005 and 2015 demonstrated that upper secondary school students tend to be more critical about schooling than the lower secondary ones, while both groups tend to be much more critical than primary school learners. Enjoyment and motivation have been demonstrated to gradually decrease with age and school level. The reason for the younger students' satisfaction with the school's offerings lies most probably in two areas: lack of formal evaluation eliminates pressure to get good marks, but also, as researchers put it, education in primary schools tends to be more play-oriented and, therefore, offers more opportunities for pupils "to follow their natural curiosity and be engaged in their own learning" (OECD, 2005, p. 79; OECD, 2015). Decreased enjoyment in older learners may also spring from the fact that - as the research demonstrated - "students do not have a one-dimensional understanding of what schooling is about. Schools represent many different things: places to learn, places to meet friends, and places to get the credentials to get ahead in life" (OECD, 2005, p. 88) - a phenomenon also identified ten years later in a series of case studies (OECD, 2015).

Dissatisfaction can be heard from parents, mainly the educated ones living in urban areas, who stress the need for personality development and problem-solving skills. Parental attitudes are extremely important in the OECD analysis, as family background proved to be the best predictor of educational achievement. Strong criticism directed at the lack of soft skills development comes also from business communities. At the same time, data collected in the Teaching and Learning International Survey have in the last decade been showing worrying degrees of teachers' dissatisfaction in 34 countries as more than 80 per cent of those questioned felt undervalued and cited a lack of influence on administrative and budgetary decisions. They also noted that the only sphere on which they could have an impact was the classroom, although even there they were far too rarely listened to (OECD, 2013). Data collected in the last TALIS survey reveal increasing problems with classroom discipline, especially in primary and lower secondary schools of 48 countries under research, 
a phenomenon adversely affecting not only learning outcomes but also teachers' self-confidence (OECD, 2018a, p. 108).

Organizational problems connected with infrastructure and teacher provision seemed under control in the EU member states, as the last international comparisons lead us to conclude (Baidak et al., 2017: OECD, 2018b), yet attempts to raise the quality of language education in particular during the first decade of the 21st century have not brought satisfactory results (Heyworth, 2013) and no improvement in overall learning outcomes has been noted over the last decade (OECD, 2018b). The discrepancy was usually attributed to insufficient teacher awareness of individual learner variables - anxiety, willingness to communicate and motivation. One learner factor, however, was overlooked and has never been properly addressed, namely that of attention - the phenomenon to which we now move.

\section{The Concept of Attention}

Attention as the flexible control of limited computational resources (Lindsay, 2020) is defined as a cognitive process enabling the individual to select a stimulus from a multitude of stimuli coming from the environment and process information it carries (Zanto \& Gazzaley, 2009). Attention presupposes a certain speed of individual reactions, a degree of alertness which makes it possible to select a salient stimulus out of a vast number of competing ones. Selection takes place through subconscious prioritization of stimuli and facilitates goal-directed behavior manifested in maintaining concentration on the stimulus considered relevant in a given context. The selection process is possible due to the inhibition of stimuli considered irrelevant in order to prevent distractibility and concentration loss, often referred to as mind wandering, although intentional and unintentional mind wandering should be distinguished (Seli, Risko, \& Smilek, 2016). Suppression of irrelevant stimuli should be long enough to enable task completion, which presupposes the ability of an individual to self-regulate behavior (Humphreys \& Sui, 2016; Foster \& Levie, 2016). Difficulties in any of the stages listed above result in attention deficit, a phenomenon best examined in learners suffering from ADHD (Merell, Sayal, Tymms, \& Kasim, 2016). Attention has a shifting nature, and any battle won is not won for long. Several types of attention have been distinguished; immediate attention attracted via a sudden emotion; voluntary attention focused on the initiative of the learner; non-voluntary attention attracted by a sudden, unexpected stimulus while performing another activity and involuntary attention when a task has been imposed and cannot be ignored for fear of consequences. Attention is linked to 
working memory in which the component of WM referred to as central executive and situated in the frontal lobes (Baddeley, 2003; Scolari, Seidl-Rathkopf, $\&$ Kastner, 2015) is responsible for executive attention and considered "principal in determining individual differences in WM span" (Biedroń, 2012, p. 82).

It follows that in pedagogical contexts what teachers colloquially refer to as "the lack of learner's attention" is an expression running counter to all the psychological definitions available, according to which attention is considered to be a preferential response based on a learner's decision to focus on one of the competing stimuli. As a large number of stimuli attack the human organism simultaneously, the result is not only the unavoidable failure of almost all of them to win in this contest, but also a shorter attention span for the victorious ones. As learners tend to select more than one stimulus, their decision results in a continuous partial attention leading to distraction or multitasking, a timesaving phenomenon taking place at the cost of quality (Barnes \& Dougherty, 2007; Sana, Weston, \& Cepeda, 2013). School learners addicted to social media and background music usually engage in multiple activities, therefore, trying to reverse this trend is difficult, if not straightforwardly impossible. Optimistic approaches point to the fact that - as research demonstrates - "people may compensate for divided-attention costs by selectively attending to the most valuable items and that factors that worsen memory do not necessarily impair the ability to selectively remember important information" (Middlebrooks, Kerr, \& Castell, 2017, p. 1103). Such compensation is, however, possible only when students are able to decide what is valuable and have some practice in prioritizing information, a skill that needs to be developed in class.

All this means that learners are always attentive and the problem lies in the fact that they do not attend to what the teacher planned to function as learners' attention focus. Teachers' battle for learners' attention and a tendency to minimize distraction tend to be treated globally ignoring the learners' age as a mediating factor. Although young learners acquire a language subconsciously and informally from input, adolescent and adult students need consciousness to ensure effective learning. Consciousness makes it possible to notice stimuli which then enter the working memory. Noticing and processing are a sine qua non condition for learning to take place (Schmidt, 1990), neither of the two being possible without attention, now more commonly analyzed as part of short-term and working memory.

Attempts at winning the race for attention call for the identification of factors stimulating it. These are: novelty, expectancy, contrast and high intensity together with interest determining motivation, a factor crucial to both attention and learning. The role of emotions cannot be underestimated. Teachers' difficulty with preventing their learners' mind wandering increases when group interaction produces strong emotions. As emotions elicit immediate attention, the teacher's battle for attention becomes a battle of and for emotions. Positive 
emotions correlate with higher selectivity and lower distractibility levels, while negative emotions adversely influence the process (Kilingsworth \& Gilbert, 2010; Pacheco-Unguetti \& Parmentier, 2014), hence the value of good teacherstudent and student-student rapport, a suggestion omnipresent in all teacher education programs.

Emotions immediately bring about attention and as friendly classroom atmosphere correlates with achievement, positive psychology promotes praise. Yet, although successful teachers praise twice as often than others, the amount of their critical remarks is not reduced. Positive feelings are not always desirable; research on optimists demonstrates that they are characterized by quick judgement, superficial information processing, less systematic thinking, unrealistic decision-making and less careful observation which makes them less valuable witnesses (Forgas, 2007; Forgas, Vargas, \& Laham, 2005). Addiction to praise can also reduce levels of motivation and autonomy. What is more, suppressing negative emotions leads to their greater accessibility, which might be counterproductive if self-regulation fails. (Weiner, 2006). Attention, therefore, benefits from positive emotions, although not at the cost of suppressing critical remarks useful as constructive feedback or expressions of negative feelings surfacing in class life.

When students are considered inattentive, teachers tend to attribute it to laziness. The issue is, however, more complicated. Mediating factors such as family situation, transport, lack of sleep and overburdening with extracurricular activities are often responsible for mind wandering. The reason for mind wandering can lie in difficulty to give attention to one object, activity or task. It can also lie in the lack of ability to maintain the same level of concentration for a longer time. Sometimes the problem can be attributed to a variety of learning difficulties the most important of which is Attention Deficit-Hyperactivity Disorder (ADHD). Sometimes the reason lies in monotony which occurs when a stimulus is repetitive and attention previously elicited has been lost, but also when stimuli are too similar adversely affecting concentration. It can also lie in under-stimulation producing boredom when, out of numerous stimuli, none is deemed interesting enough to focus a learner's attention (Pawlak et al., 2020).

Attention is strongly connected with motivation. Permanent lack of stimulating factors may result in amotivation, while in most cases unpleasant events experienced in the past produce demotivation. Remotivation is, however, always possible. Very high levels of motivation strengthen both attention and concentration leading to the so-called directed motivational current (Dörnyei, 2005; Dörnyei, Henry, \& Muir, 2016) or even to the flow phenomenon when work and pleasure start merging (Csikszentmichalyi, 2008). Conversely, motivation disappears, attention is lost and boredom creeps in when the task is imposed on the learner, but also when payoff is deemed not worth the effort. The learner 
withdraws which can also happen when the material is either too easy, hence not stimulating enough, or too difficult, hence not likely to guarantee payoff. The student's verbal and/or non-verbal message is, therefore, one of the following: Not much is going on/Enough, but it is not what I want/Not my choice, I simply had to do it/It is not worth my effort/I simply can't concentrate/I am full of negative emotions anyway. The learner then passes through several stages moving from indifference to displeasure and then to the search for new, stimulating factors. If none are found or if those found elicit teacher's criticism-the situation breeds either learner's apathy which is a challenge for the teacher or aggression which is a challenge for the whole school community (Goetz et al., 2013; Kruk, Zawodniak \& Chumas, 2017). The teacher has an outstanding role to play as didactic procedures have been found to be more important than learner's self-reported motivation (Guilloteaux \& Dörnyei, 2008).

War on attention does not only mean a series of battles against competing classroom stimuli coming from peers. It also means dealing with lifestyles and coping with the speed of the modern world with its plenitude of institutions engaged in what is often referred to as the corporate arms race for attention and the plenitude of stimuli produced by the media. The following question, therefore, arises: What can teachers do to win this race for education and the learners' personal development and what can teacher educators do to help them?

\section{Postulates for Teacher Education Programs}

As attention is crucial for learning, we need to understand its functioning to efficiently manage the language class and effectively achieve lesson objectives. Pre-service teacher education programs, however, mainly concentrate on theories and global teaching methods, lesson structure and test-based assessment, while in-service workshops understandably focus on age groups and types of educational institutions served by course participants. Individual variables tend to be dealt with in the course of reflective practice which has gained a high status in teacher education of all levels (Gabryś-Barker, 2012; Krajka, 2012; Werbińska, 2017). What seems important, though often neglected, is the need for a didactic toolkit designed for trainees in order to provide them with certain strategies, but also with food for thought and reflection. Focus on valuable techniques which can help them in their battle for learners' attention would be most helpful in pre- and in-service teacher education courses. Issues worth including could encompass verbal and nonverbal techniques on the one hand and those useful in the teaching and in 
assessment processes on the other. Their didactic value can only be determined for a particular group of students and sometimes even for a particular lesson, generalizations are, therefore, not well justified.

Initial steps in professional induction need to first address negative aspects of modelling behavior remembered from trainees' own school days. Not infrequently did their teachers use certain attention-attracting techniques to stimulate passive students and/or to redirect attention of those who respond to competing stimuli other than the didactic ones offered during the lesson. Unfortunately, a large group of these techniques were-in the spirit of those school times-based on criticism and blame typical of autocratic teaching styles and domination strategies which blur the distinction between achievement and effort by using the grading system to punish undesired behavior. In face to face classroom contact, power strategies ruin constructive interaction by negative, personal remarks breeding aggression or by delegating the problem to other individuals such as school principals or parents, which reveals the teacher's helplessness. All of them attract learners' attention, though not in the way desired as emphasis is given to the teacher-student conflict rather than to the learning task.

What is often deeply ingrained in many trainees' memories is their school teachers' ways of attracting attention by eliciting negative emotions such as shame, irritation or anger elicited through critical remarks connected with certain types of feedback given to learners in connection with their classroom behavior or with their educational attainment. Comments breeding aggression usually take the form of personal 'You-messages' of the you always... kind. Here a constructive element of teacher education can be introduced: according to the Congruent Communication Theory, feedback in this form tends to be rejected and as such is didactically useless and, what is more, ruins teacher-student rapport, destroying chances for fruitful interaction (Ginott, 1972; Spitzberg \& Cupach, 2007). For classroom management purposes expressive 'I-messages' describing the teacher's feelings about the situation are more effective as they are either accepted or ignored with no negative emotions to follow. 'It-messages' which point out the problem, describe it and suggest constructive solution are the most valuable and tend to be fully accepted by the addressee.

Another aspect seems worth pointing out here. Constructive feedback manifested in the appropriate choice of message format shows the learner ways of evaluation which do not base on power and authority, but on a precise diagnosis springing from observation and expertise. This means that - as the Elaboration Likelihood Theory puts it - central rather than peripheral processing is taking place in the mind (Petty \& Wegener, 1999). It is, therefore, important for the teacher to be aware of impulsive tendencies and, in consequence, to be able to block reactions to be avoided and choose feedback formats conducive to learning. It is also indispensable for the teacher to have at least some knowledge of 
the learner's reactions as today we know that students with high ego-protection do not easily take critical remarks, remember negative feedback for a long time, but at the same time may be distrustful of praise, doubting the authority of the person who praises them, while students with tendencies to enhance their ego tend to actively seek praise, remember praise for a long time and respect the person praising them (Sedikides \& Skowronski, 2009).

Elimination of subconscious modelling and replacing it with constructive patterns paves the way for the introduction of useful didactic techniques. The most popular of the verbal ones draw on attractiveness of the teaching content, selecting topics of interest and enjoyable activities. Trainees should, however, reflect on the fact that this seemingly effective path is often less effective than planned as teachers tend to select what they presume would be interesting and enjoyable for students, a type of content not always perceived by the learners as such. On the other hand, students' needs may prove so diverse that it is extremely difficult for the teacher to satisfy them given curricular constraints; teacher-student consultations are, therefore, needed. The race for attention may be won, but the attention gained does not go to learning; it is given to negotiation often used to gain time, especially if prolonged negotiations are conducted in the mother tongue. If the problem does not arise, yet learners attention is misdirected - an unexpected code-switch from L2 into the mother tongue may serve the purpose, though it works only for teachers who conduct their lessons in the target language as otherwise the surprise factor of such a brief intervention is lost.

Simple and effective, but not so frequently used classroom techniques to be recommended are, for example, the feed-back technique, whereby learners are not informed of teaching aims at the beginning of the lesson, but engage in their inductive discovery at the end of the session or the traffic light technique based on end-of-lesson color cards where a red card signals lack of skill, a yellow one shows that a skill has been developed only partially and a green one informs of learner's difficulties. Attention attractors can also be found among self- assessment techniques based on the expectancy factor such as self-assessment prediction where students try to determine the grade they expect, compare the grade received with their expectations and check their own work one more time against the grading criteria; or a peer assessment procedure according to a two stars and a wish formula with two aspects to praise and one to be considered for the future. What is also effective, is guessing the upcoming test technique whereby students are encouraged to prepare their own test items of the type they expect to appear on a test.

Resources can also be found in non-verbal communication. Silence is the simplest, though often forgotten option which proves powerful on two conditions: first, when it is unexpected and, second, when it is combined with intense gaze. Its psychological function is based on the surprise factor, which 
makes it useful for teachers whose conversational style tends to be one usually referred to as the high involvement style characterized by fast speech, expressive intonation, short hesitation pauses and immediate starts when others finish their turn. Silence as attention attractor is not effective for those whose way of speaking is described as the high considerateness style marked by slow speech, long hesitation pauses, intonation and delayed start when others finish talking and less expressive pitch (Tannen, 2005; Tannen, 2012). Silence as a classroom management technique used for disciplinary purposes enables the teacher not to depart from the original lesson scenario, an additional benefit impossible if verbal strategies are used (Witosz, 2006).

Gesture is another obvious choice, considering it does not take time needed for language teaching and can even support contact and comprehension at the same time playing a management function. So far teachers have been interested in the conscious use of gesture for two reasons: signaling approval / disapproval and error correction. Today explicit instruction in the use of gestures which should be part of teacher education takes place solely in courses of business English or English for public speaking where persuasive and manipulation skills are being developed. What seems to be relatively well popularized in language teaching methodology is a specific use of gestures to signal grammatical errors, but these are beyond the scope of our reflection here as they relate to the learner's utterance, that is, a situation in which the learner's attention is already in harmony with the teaching focus. Gestures attempting to hold attention for a longer time or to attract attention lost can take several forms depending on the speaker's intention (Komorowska, 2018). Attention is more likely to be attracted when gestures bridge an information gap needed to complete a task. For that purpose teachers can use deictic gestures which point to an object, thus supporting comprehension of a difficult or unknown word or replacing missing nouns, but also iconic gestures which present the shape of objects spoken about. In order to elicit speech the teacher may use metaphoric gestures which carry a specific meaning, such as a hand placed on the heart, with a subset of emblems, that is, gestures carrying one meaning evident to every member of a given speech community. To hold learners' attention teachers can use beats which signal the rhythm of their speech, and provide implicit non-verbal instruction in suprasegmentals.

If teachers decide to explicitly concentrate learners' attention on the use of gesture and raise awareness of its individual use, pair work or group work rather than the desk-to-desk format is recommended during which one student gives a brief oral presentation and the other one gives feedback describing body posture, facial expression and gestures which have been used, their intention and the listener's perception of their function, value, and quality. Reaction of the observed and possible comments by the other members of the group end the activity which is usually considered attractive in the classroom. The 
teacher's role is to create relaxed learning environments, offer model sentences to prevent undesired forms of criticism which would block further communication and harm interpersonal relations in the classroom, and give tips on verbal and non-verbal signals of attentive and respectful listening. Encouraging learners' gesticulation in the classroom is not likely to reduce student speaking time as no more than 7 per cent of interlocutor's responses have been found to consist of gestures only (Puppel, 2013). What is more, verbal signals attract attention, bodily engagement enhances motivation on task, and conversations accompanied by gestures are perceived as more smooth and natural (Sidnell \& Stivers, 2012).

\section{Controversial Issues}

Arguably the most important controversy concerns the value of new technologies which are believed to motivate students and are today part of their everyday life. Their role in unexpected situations, such as pandemics, is not at all questionable; there is, however, uncertainty about the value of for example, the use of mobile phones during face-to-face lessons or of various applications used during the preparation of homework assignments. Controversy started when the European Union's international comparative analysis of educational attainment in languages surveying 50 thousand 15 -year-olds in 15 countries with 18 school systems proved completely unexpected in the section devoted to new technologies. In the times of enthusiasm for promising solutions, factors which do not correlate with FL test scores were identified as: teacher's use of ICT outside lessons for teaching, teacher's use of ICT devices when teaching and teacher's use of web content for teaching. What is more, strong negative effect of ICT use at home was found, with some positive effect only on listening comprehension. Similarly negative effects were noted of time spent on preparing students for tests as well as of time spent on homework. General report stated "no positive effect on average scores on the language tests for any of the skills" (European Commission, 2012, p. 83).

The explanation of the data quoted above, which have every right to be perceived as counter-intuitive, most probably lies in the selection of stimuli and the subsequent direction of attention which tends to orient itself towards hardware rather content. It may also lie in the low value of didactic content and misuse of new technologies which more and more often lead to treating life as a competition during which the goal of people and institutions is to attract our attention. The phenomenon is extensively discussed by Tristan Harris, a design ethicist formerly working at Apple and Google who analyzes ways in which 
creators of big international corporations with authors of advertising campaigns 'hijack our attention' and warns against losing control over our time and life. Today he heads the Centre for Humane Technology (www.humanetech.com) whose activity is not directed against new technologies, but consists in planning strategies to help users identify their own needs rather than let technological giants create artificial needs for commercial purposes.

Another controversial issue is the phenomenon of teachers' attention, a phenomenon rarely discussed by educators understandably concentrating on learners. Whether their attention is evaluated positively or considered misdirected is very often a matter of opinion. In didactic contexts, for example, teachers' attention often goes to grammatical errors. These are usually noticed not only as a consequence of long educational tradition, but also because mistakes in this field are often perceived as indices of the learner's attitude to language learning and symptoms of disrespect to schools and teachers. They are also noticed, because - alongside spelling - grammar is an aspect of a foreign language where objective assessment is possible. It also goes to grammar because teachers treat the type and number of mistakes as an important piece of pedagogical information on how diligently the learner works in class and completes assigned homework. Yet, goal-directed corrective behavior by the teacher is often much better justified in tasks designed to develop speaking skills, when attention targets content, rhythm, intonation and fluency. Balancing objectivity of assessment and the communicative value of the message in teacher's attention management is a difficult decision, not infrequently mediated by internal regulations of the employing institution.

On a more general plane, teachers often feel insecure when it comes to making decisions on how to manage their attention when offering corrective feedback and-considering the multitude of conflicting opinions in the literature on the subject - they have every right to be confused. Academic sources are abundant in books and articles on Englishes of the World and the role of English as a global language functioning as the lingua franca of the modern times (Jenkins, 2014). Most of these texts undermine the status of the nativespeaker as a criterion of linguistic standards, and thus legitimize ELF users of the international language. On the other hand, characteristics of speech samples produced by speakers of ELF are similar to those produced by B1/B2 speakers of English as a foreign language. It is, therefore, understandable that teachers may start hesitating when it comes to correcting mistakes made by intermediate, upper-intermediate or advanced students, especially the relatively fluent ones. Yet in school language learning future needs of our students are unknown and, in the era of mobility, it would be dangerous to assume that they will never live in English-speaking countries and are likely to communicate with other ELF speakers only. Yet, as Alan Davies (2015) states in his interview for LAQ, we have no other criterion than the native-speaker who 
will remain a model, which does not mean that this model must be identical with the educational goals selected for a given program. For the time being, developing proficient speaking skills results in fact in less rigor in the teaching of grammar and pronunciation where criteria have been shifted from accuracy to acceptability.

Redirecting teacher's attention from what learners consider to be the focal point is also subject to controversy. Teachers are often encouraged to take learners' communication anxiety into consideration and refrain from intervention or use delayed correction in the hope that this procedure will attract learner's attention without ruining their self-esteem and blocking fluency. Students, however, consider immediate error correction part of the teacher's job and tend to suspect teachers who tend to ignore mistakes of neglect or incompetence. The lack of immediate correction is at the same time taken by other students to mean approval of what is being produced which may lead to promoting mistakes in the classroom. Recast presented in a voice soft enough not to stop a learner's utterance, but clear enough to inform everybody of the correct form seems to be a better option, yet opinions here remain divided. A similar redirecting process takes place when teacher's attention goes to learners' classroom behavior taken as an index of their attitude towards school and the teacher. Their behavior towards their peers is, however, more than infrequently much more important than their behavior vis-à-vis the teacher as bullying and hate speech are easy to overlook when attention is directed to unpleasant, though much less dangerous, behavior. Misdirected attention on the part of the teacher is definitely among topics rarely addressed in the course of pre- and in-service teacher education.

\section{Conclusion}

In pre- and -in-service teacher education curricula attention does not seem to be granted the status it deserves. As a factor crucial for learning, it should be attracted to stimuli relevant for the learning process, yet in the influx of stimuli, there is no certainty that didactic procedures will automatically ensure goal-oriented behavior in the school context. Not all verbal techniques function effectively and some, especially those based on domination strategies, are counterproductive causing boredom, negative attention, frustration or aggression. Content interesting for students and positive teacher-student rapport always help, yet without appropriate forms of feedback they are not likely to guarantee full success. Extra resources need to be sought among less frequently used classroom procedures, such as innovative self-assessment and peer-assessment 
techniques as well as in non-verbal strategies involving silence and gesture. Making trainees aware of the need for constructive attention attracting techniques is today one of the primary goals of teacher education.

It should, however, be remembered that to give attention to others, teachers themselves also need attention not only from their learners, but also from parents and administrators. Evidently they do not get enough considering the data collected in the TALIS survey quoted above. If more than four-fifths of a huge sample of European teachers feel dissatisfied and undervalued, it is crucial to start searching for underlying processes. Research on causes of this undesirable state of affairs was launched by the OECD by a group of researchers who came up with a list of four basic factors - a lack of autonomy in professional decisions (the intrinsic component), unpleasant atmosphere of the workplace (the external component), barriers in professional development resulting in a blocked career path (the temporal component) and stress or burnout caused by lack of success and limited options. The OECD report explicitly states that positive atmosphere in the staff and administrative decisions respecting teachers and supporting their work are crucial for the quality of education: "Teachers cannot make progress unless they are happy" (Looney \& Wiliam, 2015). If governments expect to see high educational achievement in their countries, they must invest in schools and teachers.

\section{References}

Baidak, N., Balcon, M.-P., \& Motiejunaite, A. (2017). Key data on teaching foreign languages at schools in Europe. Brussels: EURYDICE.

Barnes K. A., \& Dougherty M. R. (2007). The effect of divided attention on global judgment of learning accuracy. American Journal of Psychology, 120, 347-359.

Baddeley, A. D. (2003). Working memory and language: An overview. Journal of Communication Disorders 36, 189-208.

Biedroń, A. (2012). Memory abilities in gifted foreign language learners. In M. Pawlak (Ed.), New perspectives on individual differences in language learning and teaching (pp. 77-96). Berlin: Springer.

Council of Europe (2001). Common European framework of reference for languages. Learning, teaching, assessment. Cambridge: Cambridge University Press.

Council of Europe (2018). Common European framework. Companion volume. Strasbourg: Council of Europe.

Csikszentmihalyi, M. (2008). Flow. The psychology of optimal experience. New York: Harper Perennial Modern Classics.

Davies, A. (2015). An interview. In A. J. Kunnan (Ed.), Talking about language assessment. The LAQ interviews (pp. 35-50). London: Routledge.

Dörnyei, Z. (2005). The psychology of the learner. Individual differences in second language acquisition. Mahwah: Lawrence Erlbaum. 
Dörnyei, Z., Henry, A., \& Muir, C. (2016). Motivational currents in language learning. Frameworks for focused interventions. London: Routledge.

European Commission (2002). Education and training in Europe: Diverse systems, shared goals for 2010. Brussels: EU Publishing.

European Commission (2005). A new framework strategy for multilingualism. Communication from the Commission to the Council the European Parliament, the European Economic and Social Committee and the Committee of the Regions. Brussels: EU Publishing.

European Commission (2012) SurveyLang - First European survey on language competences. Final report. Brussels: EU Publishing.

European Commission (2019). Key competences for lifelong learning. Brussels: EU Publishing.

Forgas, J. P. (2007). When sad is better than happy: Mood effects on the effectiveness of persuasive messages. Journal of Experimental Social Psychology, 43, 513-528.

Forgas, J. P., Vargas, P., \& Laham, S. (2005). Mood effects on eyewitness memory: Affective influences on susceptibility to misinformation. Journal of Experimental Social Psychology, $41,574-588$.

Forster, S., \& Lavie, N. (2016). Establishing the attention-distractibility trait. London: Sage.

Gabryś-Barker, D. (2012). Reflectivity in pre-service teacher education. A survey of theory and practice. Katowice: Wydawnictwo Uniwersytetu Śląskiego.

Ginott, H. (1972). Teacher and child. London: Macmillan.

Goetz, T., Frenzel, A., Hall, N., Nett, U., Pekrun, R., \& Lipnevich, A. (2013). Types of boredom. Experience sampling approach. Motivation and Emotion, 38(3), 401-419.

Guilloteaux, M. J., \& Dörnyei, Z. (2008). Motivating language learners. A classroom-oriented investigation of the effects of motivational strategies on student motivation. TESOL Quarterly 42, 55-77.

Heyworth, F. (2013). Applications of quality management for language education. Language Teaching 46/3, 281-315.

Humphreys, G. W, \& Sui, J. (2016). Attentional control and the self: The Self-Attention Network (SAN). Cognitive Neuroscience 7, 5-17.

Jenkins, J. (2014). Global Englishes. London: Routledge.

Killingsworth, M. A., \& Gilbert, D. T. (2010). A wandering mind is an unhappy mind. Science, 330, 932-934.

Komorowska H. (2018). Speech and its silent partner: Gesture in communication and language learning. In M. Pawlak \& A. Mystkowska-Wiertelak (Eds.), Challenges of second and foreign language education in a globalized world (pp. 73-88). Berlin: Springer.

Krajka, J. (2012). The language teacher in the digital age. Towards a systematic approach to digital teacher development. Lublin: Wydawnictwo UMCS.

Kruk, M., Zawodniak, J., \& Chumas, J. (2017). Towards conceptualizing boredom as an emotion in the EFL academic context. Konin Language Studies 5/4, 425-441.

Lindsay, G. W. (2020). Attention in psychology, neuroscience and machine learning. Frontiers in Computational Neuroscience, https://www.frontiersin.org/articles/10.3389/fncom.2020.00029/full (accessed 4.05.2020).

Looney, J., \& Wiliam, D. (2015). England: Implementing formative assessment in high stakes environment. In OECD, Improving learning in secondary classrooms (pp. 128-149). Paris: OECD Publishing.

Merrell, C., Sayal, K., Tymms, P., \& Kasim, A. (2016). A longitudinal study of the association between inattention, hyperactivity and impulsivity and children's academic attainment at age 11. Learning and Individual Differences 53, 156-161. 
Middlebrooks, C.D., Kerr, T., \& Castell, A. D. (2017). Selectively distracted. Divided attention and memory for important information. Psychological Sciences \& Social Sciences, 28(8), $1103-1120$.

Mullis, I. V. S., Martin, M. O., Foy, P., \& Hooper, M. (2017). PIRLS 2016. International results in reading. IEA/Boston College: TIMMS \& PIRLS International Study Center.

OECD (2005). Schooling for tomorrow. Demand for schooling. Perception, participation and choice. Paris: OECD.

OECD ( 2009). The teaching and learning international study. TALIS 2009 results. Paris: OECD.

OECD (2015). Formative assessment. Improving learning in secondary classrooms. Paris: OECD.

OECD (2018a). The teaching and learning international study. TALIS 2018 results. Paris: OECD.

OECD (2018b). Programme for international student assessment. PISA 2018 results. Paris: OECD.

Pacheco-Unguetti, A. P., \& Parmentier, F. B. R. (2014). Sadness increases distraction by auditory deviant stimuli. Emotion, 14(1), 203-213.

Pawlak, M., Zawodniak, J., Kruk, M. (2020). Boredom in the foreign language classroom. Cham: Springer.

Petty, R. E., \& Wegener, D. (1999). The elaboration likelihood model. Current status and controversies. In S. Chaiken Y. Trope (Eds.), Dual process theories in social psychology (pp. 41-72). New York: Guilford.

Puppel, J. (2013). Facework and gestures: A preliminary analysis of the communicative power of human performative non-verbal practices, Scripta Neophilologica Posnaniensia 13, 85-90.

Sana F., Weston T., \& Cepeda N. J. (2013). Laptop multitasking hinders classroom learning for both users and nearby peers. Computers \& Education, 62, 24-31.

Schmidt, R. W. (1990). The role of consciousness in second language learning. Applied Linguistics 11, 129-58.

Scolari, M., Seidl-Rathkopf, K. N., \& Kastner. S. (2015). Functions of the human frontoparietal attention network: Evidence from neuroimaging. Current Opinion in Behavioral Sciences, 1, 32-39.

Sedikides, C., \& Skowronski, J. A. (2009). Social cognition and self-cognition. European Journal of Social Psychology 39, 1245-1249.

Seli, P., Risko, E. F., \& Smilek, D. (2016). On the necessity of distinguishing between unintentional and intentional mind wandering. Psychological Science 27, 685-691.

Sidnell, J., \& Stivers, T. (2012). The handbook of conversation analysis. London: Blackwell.

Spitzberg, B. H., \& Cupach, W. R. (2007). The dark side of interpersonal communication. New York: Lawrence Erlbaum.

Tannen, D. (2005). New York Jewish conversational style. In S. Kiesling \& C. Bratt Paulston, (Eds.), Intercultural discourse and communication (pp. 136-149). Malden, MA: Blackwell.

Tannen, D. (2012). Conversational signals and devices. In L. J. Monaghan, J. Goodman, J. M. Robinson (Eds.), A Cultural approach to interpersonal communication (pp. 157-167). Oxford: Wiley-Blackwell.

Weiner, B. (2006). Social motivation, justice and the moral emotions: An attributional approach. Mahwah, New Jersey: Lawrence Erlbaum Associates.

Werbińska, D. (2017). The formation of language teacher professional identity. Słupsk: Wydawnictwo Naukowe Akademii Pomorskiej.

Witosz, B. (Ed). (2006). Style konwersacyjne. Katowice: Wydawnictwo Uniwersytetu Śląskiego. 
Zanto, Th. P., \& Gazzaley, A. (2009). Neural suppression of irrelevant information underlies optimal working memory performance. The Journal of Neuroscience 29(10), 3059-3066.

www.ecml.at

www.humanetech.com

Hanna Komorowska

\title{
TDas Phänomen der Aufmerksamkeit in der Lehrerbildung und dessen Bedeutung für die Qualität des europäischen Schulwesens
}

\author{
Zusammenfassung
}

Der Artikel präsentiert Überlegungen zu den Ursachen für Missverhältnis zwischen dem durch europäische Einrichtungen im Bildungsbereich geleisteten Aufwand und der an Umsetzung von Programmzielen gemessenen Qualität einzelner Bildungssysteme. In Anbetracht dessen, dass sich die beunruhigenden Bildungstrends hauptsächlich auf dem Niveau der Schulklasse bemerken lassen, scheint es relevant zu sein, dass man in erster Linie die psychologischen und nicht die organisatorischen Faktoren unter die Lupe nimmt. Im Artikel wird die These gestellt, dass man auf der Suche nach Gründen für Misserfolge das Phänomen der Aufmerksamkeit analysieren sollte, während bisher die Motivation im Fokus des Interesses stand. Es wurden daher die Typen und Aspekte der Aufmerksamkeit, die Tendenzen zu deren Umlenkung, sowie die Techniken zur Gewinnung und Aufrechterhaltung von Schüleraufmerksamkeit erläutert, um deren Ablenkung entgegenzuwirken. Darüber hinaus wurde die Frage der Ausrichtung von Lehreraufmerksamkeit angesprochen. Auf dieser Grundlage wurden die Forderungen an Lehrprogramme und die Fort- bzw. Weiterbildung der Lehrer formuliert, die man um solche verbalen und nonverbalen Förderungsstrategien für Anziehung und Aufrechterhaltung von Schüleraufmerksamkeit erweitern sollte, die mit keiner Notwendigkeit, das vorher entwickelte Unterrichtsszenario zu modifizieren, zusammenhängen würden.

Schlüsselwörter: Fremdsprachenlernen, Bildungsqualität, Aufmerksamkeit, Lehrstrategien, Lehrerbildung 
